\title{
THE PROGRESS OF SANITATION IN GREAT BRITAIN
}

\author{
By Dr. A. K. Chalmers, D. P. H. (Camb.), \\ Medical Officer of Health, Glasgow, Scotland.
}

To the hopeful worker in hygiene, it may be said that the beginning of the new century has brought with it some suggestion of an ever-widening domain within which his energies may find new scope for their exercise. The historian of nineteenth century sanitation in Great Britain might with reason date its origin (albeit it was an unconscious one) in the system of factory legislation which began with the "Health and Morals of Apprentices Act I802"; but to appreciate the mental atmosphere out of which this legislation emerged, he must have recourse to the growth of the "New Humanity" in British politics (as Sir John Simon has so happily phrased it), and that "larger sympathy of man with man" which John Richard Green found so characteristic of the eighteenth century.

And so it is an easy step from the first effort to reclaim the children from the uncontrolled evils of a recently introduced factory system to the complementary movement which the Poor Law Commission of 1834 inaugurated in their report of that year, and which, together with the growth of a spirit of co-operation among the adult workers, did so much to reclaim industrial England from the poverty into which it had sunk in the first part of last century.

It is true that sanitary endeavor, in the form at least of an organized administration, as yet scarcely existed, but its foundations were being securely laid in the accumulating knowledge of the Poor Law Commissioners regarding the home conditions of the industrial poor, and the part which these played in disposing to the disease which lay behind so much of their poverty. Although it was thus early recognized that the problems of poverty and sanitatation had much in common, the time had scarcely come when their unity could be clearly recognized. For to the hygienist of the middle of the nineteenth century, the widespread incidence of the major infectious diseases, and their tendency every now and again to [273] 
leap into epidemics of considerable magnitude, made their control a question of imperious necessity. He saw the industrial centres of Britain scourged with ever recurring epidemics of typhus fever; cholera, even so recently as the 6o's decade, spreading westward across Europe, and apparently presaging a renewal of the outbreaks in Britain which the second quarter of the century had witnessed, pulmonary phthisis moving apparently uncontrolled among the very flower of the industrial community, and, like a good workman, he devoted his energies to the work which lay nearest to hand, and most urgently demanded should be done. But while he accomplished much for the well-being of his own generation, he did more for the generation which was to follow and for humanity in general by laying the basis for the conception that these diseases and others of like character were Nature's method of teaching mankind that the massing of populations in large centres was more than the mere aggregation of human beings, with the wants of the individual simply multiplied by this number, but the creation as it were of an organic communal life which had new aspirations and new needs of its own. And because of this, we of a later generation, with the altered perspective which time admits of, can see the sanitary problems of to-day in probably a truer relationship to the economic basis of the life of the individual, and can recognise, as frankly contributing the results after which sanitation strives, the operation of every agency which has the promotion of individual well-being as its object. Factory legislation in Britain made provision for the education of children almost as a side issue. Now an educational code has arisen which contemplates the well-being or health conditions of the children as well as their education. Poor law legislation, rightly interpreted, aims at the repression of pauperism and the encouragement of thrift. Sanitation proposes for the individual, conditions of life and work which will satisfy the physiological demands of his system. All alike proclaim that individual efficiency is the right of manhood, and that conditions which impair it should cease.

Writing so long ago as 1883 , Sir Robert Giffen ${ }^{1}$ in dealing with

1" The Progress of the Working Classes in the Last Half Century." Lnaugural addrese as president of the Statistical Society. Delivered November $20,188_{3}$, and now reproduced in a volume on "Economic Enquiries and Studies." Vol. I. London. George Bell \& Sons, r904. 
Mr. Noel Humphreys' paper on “The Recent Decline in the English Death-rate" (which was based on a comparison of the death-rates $1838-54$ and $1876-80$ and the increased expectation of life in the latter period) observes with regard to Mr. Humphreys' conclusion that "the larger proportion" of this "is lived at useful ages and not at the dependent ages of either childhood or old age" that " the figures to be affected relate to such large masses of population that so great a change could not have occurred if only a small percentage of the population had been improved in health."

In the periods thus compared, the average duration (or expectation) of life among males arose from 39.9 to $4 \mathrm{r} .9$ years, and among females from 41.9 to 45.3 years, while Dr. Tatham has shown that in the decade, I88I-90, it further increased to 43.7 for males and 47.2 for females.

It was natural to regard these results as in some measure reflecting the work of local sanitary and other authorities during a whole generation of fairly continuous effort. Factory legislation had improved the conditions, and in many instances shortened the hours of labor. Local authorities had introduced water supplies and improved systems of drainage. Much attention had been given throughout the country to the conditions of housing, large areas of badly constructed tenements and badly arranged streets had been cleared in the large towns, and building regulations had been devised to control the erection of houses, so that the primary requirements of light and ventilation should be met, and the evils arising from unsuitability and impurity of site prevented. Continuous effort was being made to prevent the overbuilding of sites and the overcrowding of rooms; greater purity of soil water and air was constantly aimed at, and above and beyond all this, the economic condition of the worker had been improved, the purchasing power of money had increased, and the cost of food stuffs been reduced.

It was, as we have said, difficult to dissociate all these from the continued reduction in the death-rate and consequent increase in the expectation of life, so that it is not a little striking that the first call of the new century to the public health administrations to arm themselves for further effort should have been sounded on the note of physical deterioration. Some facts were adduced on which the suggestion was based, and the questions which had to be answered were-whether our material progress during the nineteenth 
century had been purchased at the cost of racial degeneration, and the whole policy of sanitary administration needed revisal.

Some earlier writers (Mr. Herbert Spencer and Mr. Lecky among others) had suggested that declining death-rates did not necessarily imply improved vitality in the survivors, but these had created no misgivings in the public conscience until the statement took the definite form just alluded to. Resulting from this, however, a committee, consisting of representatives from several departments of the government, was appointed, and the questions referred to it were as follows:

"To make a preliminary inquiry into the allegations concerning the deterioration of certain classes of the population as shown by the large percentage of rejections for physical causes of recruits for the army and by other evidence, especially the report of the Royal Commission on Physical Training (Scotland), and to consider in what manner the medical profession can best be consulted on the subject with a view to the appointment of a Royal Commission, and the terms of reference to such a commission if appointed.

"These terms of reference were subsequently explained and enlarged, as follows:

"( I) To determine, with the aid of such counsel as the medical profession are able to give, the steps that should be taken to furnish the government and the nation at large with periodical data for an accurate comparative estimate of the health and physique of the people; (2) to indicate generally the causes of such physical deterioration as does exist in certain classes, and (3) to point out the means by which it can be most effectually diminished."

It must be admitted that the advocates of the physical deterioration theory found much material ready to hand wherewith to illustrate their argument, if not to render it convincing. Happily it was also possible to show that their error lay not in the facts which they adduced, but in the generalisations which had been based on them. And here we return to a consideration of circumstances within the knowledge of every active worker in the field of sanitary administration. The statistical data on which hygiene progresses are not misleading when used with such knowledge. Our general death-rates have become reduced, our expectation of life has increased, but these facts are true only when applied to the whole population of a country or to communities thereof. The [276] 
error lies in assuming that they are equally true of all sections of a community. When the Departmental Committee, to which I have referred, proceeded to consider the conditions from which physical inefficiency springs, they cited Sir Shirley Murphy's comparison of the expectation of life in the districts of Hampstead and Southwark in London, which afford social contrasts. The expectation of life at birth in Hampstead was 50.8 years, in Southwark it was only 36.5. Again, they quoted the figures from Finsbury, London, where in a population of 14,516 persons occupying one-roomed tenements, the death-rate in 1903 was 38.9 , although the rate among occupants of four or more rooms was only 5.6, and for the whole burgh I9.6. And turning to similar evidence regarding the population of Glasgow, they quote the medical officer's figures for I9OI, which show that the general death-rate in one-roomed houses there was nearly twice that of the whole city; and the death-rate from pulmonary tuberculosis was 2.4 per thousand in one-roomed houses, 1.8 in houses of two rooms and .7 only in all the others.

Here then we have focussed for us, as it were, sections of the field within which the work of social and sanitary reform of the future lies. They form illustrations, which might be multiplied from the experience of every modern city, of a not inconsiderable multitude to whom the gospel of hygiene has hitherto failed to carry any message of healing, because the ever-present problem with them is not how to reach a higher level of living, but how to maintain life at all. It were easy to find terms of social obloquy wherewith to describe the indifference which the least fortunate among them display to any call save that of the elemental requirements of life; it is less easy to adjust the balance, when it comes to weighing their indifference against the injury which they inflict on those who equally with themselves are ill-provided with material comforts, yet, nevertheless, are possessed of a morale which only awaits opportunity to develop. For while the inefficient and indifferent, the drinker and the criminal abound among them, there is also the unskilled worker, the widow, the seamstress, the whole mass indeed of low paid and unorganized labor which is ever engaged in a merciless competition with the casual worker for employment and food and housing.

But while fully recognising this and making due allowance for the existence of a parasitic class, it were the very essence of fatalism to regard the present condition as irremediable. The danger indeed 
at the present moment is not that effort will not be made, but that it should take a wrong direction. The problem which the late Sir John Simon expressed in a phrase which his writings have made classic, "How the poor are to be made less poor," seems to assume a more hopeful form when rendered, "How is the inefficient worker to be made efficient." The social evils which result from individual ill-doing is only one phase of the problem and is not here in question. Let us frankly admit that past effort to deal with the class whom for convenience we designate the slum-dweller, has hitherto failed to make any considerable impression on him. We have displaced him from his slum; have we replaced him in active citizenship? If disappointment and a recognition of the results should tempt us hurriedly to answer that we have not,--often, at least,--there is the more reason further to enquire whether it is not because we had been anticipating that a moral revival would follow physical displacement alone. In short, is it not the case that there are social evils which, like some bodily diseases, are irremediable, save only by preventing their advent. It is easy to demolish the slum; how shall we approach the question how to prevent the formation of the class from which the slum-dweller is recruited. Let us leave aside for the moment all that can be said for the undoubted aid which the experience of the past has taught us may be obtained by regulating the site and construction of buildings, the size and overcrowding of rooms, the width of streets, the provision of open spaces and sanitary appliances, the purer air, water and soil, to which we have already alluded, and concentrate our attention for a little on the human element in it all, which is, and ever must be, the objective of our efforts.

We have seen that the evil effects of "urbanization" can to a large extent be controlled, and the most obvious proof of this lies in the fact that while the urban population of this country has increased in the last half century from about 50 to 77 per cent. of the whole, the death-rate of towns generally is as low-in some instances lower-than was the rate for the whole country at the beginning of that period. We have also seen that judged by every material and hygienic standard, the greater part of communities present no administrative problem, hygienic or otherwise, which by concerted effort they are unable to solve. And it is precisely at this point that the problem of the unreclaimed portions of our communi- 
ties emerges. These have not benefited because there has not been developed in them a desire for improvement. Let us recognize the fact that they are remnants as it were of an earlier period of civic life. "The poor perish for lack of knowledge"-they lack initiative-they are but "as children crying in the night, with no language but a cry." And so one turns to the children among them as the most hopeful point at which to commence the work of regeneration. We welcome the re-awakening interest in the hygiene of school life, because it carries with it the germ of new effort to accomplish on a broader basis the education of the children of the poor. The present writer has had an opportunity recently of conducting an enquiry into the physical condition of the children in certain schools in poorer class districts, and the following tables which were submitted to the school hygiene conference of the Royal Sanitary Institute of Britain, held in London in February, 1905, may here be reproduced.

These tables are almost self-explanatory, but the following extracts from the paper in which they were presented may assist in reading them:

"I. The children are grouped according to the size of house occupied by their parents. In this way the economic position of the family is indicated.

" 2 . The height, weight, state of nutrition and mental capacity (teacher's opinion) of the children follow closely this "economic" grading.

"3. The lowest economic grade is separated from the others by a wide interval, both with regard to nutrition and mental capacity.

"4. The constituents of certain diets are stated, from information supplied by the children, and grouped as good, medium and bad, according to the proteids and fats they contain.

"5. The weight at given ages of children living under similar conditions otherwise show an almost constant gradation, which corresponds to the quality of the diets thus grouped.

" 6 . With regard to the lowest grading, it is asked whether there is in the tables a suggestion of economic waste in applying, under present conditions, the energies of a highly trained teaching staff to the training of children who are obviously underfed.

"Bearing in mind what I have said as to the danger of generalizing from insufficient data, there is notwithstanding, I think, 
Weight of Children in Relation to Diet (Families in Two-Room ApartMents). (Dr. Kay.)

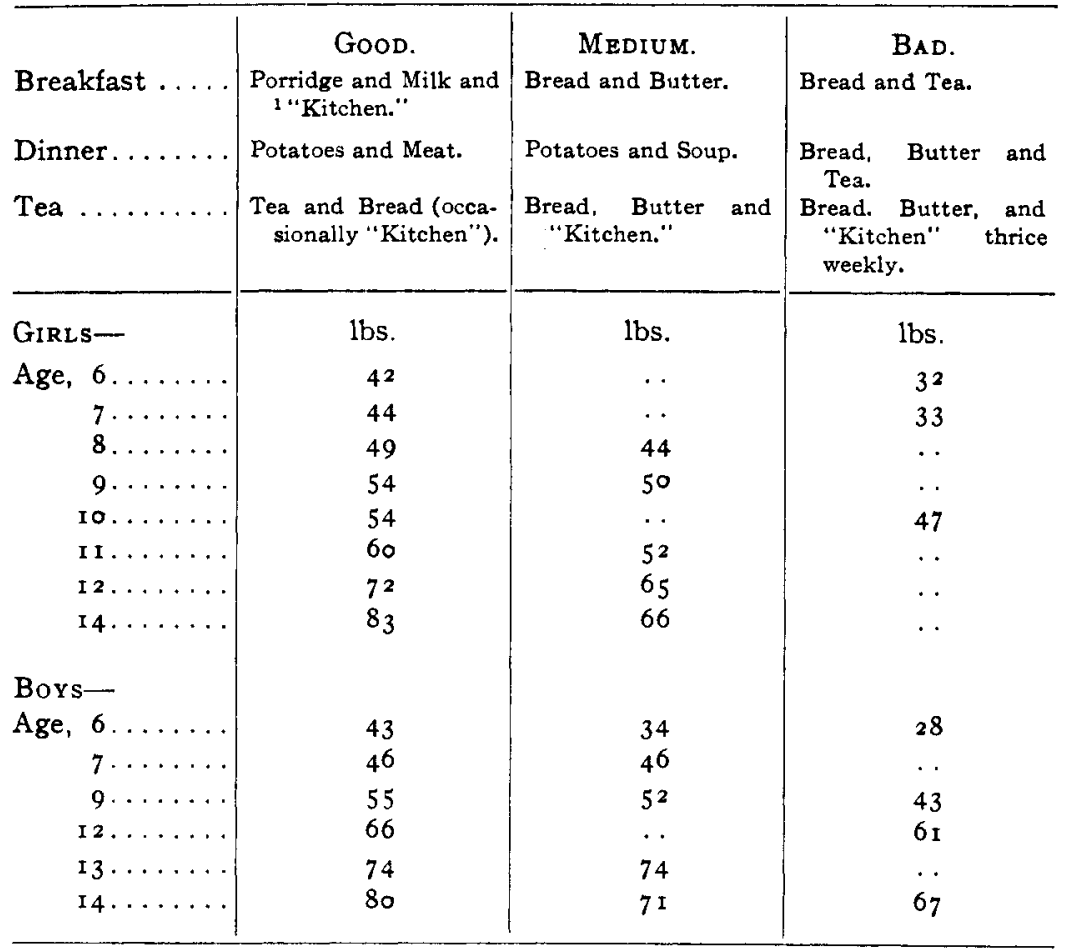

Comparison of Children According to Stze of House (Boys).

\begin{tabular}{|c|c|c|c|c|c|c|c|c|c|c|}
\hline \multirow{3}{*}{$\begin{array}{c}\text { Death } \\
\text { Rate } \\
\text { per } \\
\text { 1000 }\end{array}$} & \multirow{3}{*}{$\begin{array}{l}\text { Size of } \\
\text { House } \\
\text { in } \\
\text { Rooms }\end{array}$} & \multirow{3}{*}{$\begin{array}{c}\text { Mean } \\
\text { Height } \\
\text { in } \\
\text { Inches. }\end{array}$} & \multirow{3}{*}{$\begin{array}{c}\text { Mean } \\
\text { Weight } \\
\text { in } \\
\text { Pounds. }\end{array}$} & \multicolumn{7}{|c|}{ STATED AS PERCENTAGE. } \\
\hline & & & & \multicolumn{3}{|c|}{ State of Nutrition. } & \multicolumn{4}{|c|}{$\begin{array}{l}\text { Mental Capacity (Teacher's } \\
\text { Estimate). }\end{array}$} \\
\hline & & & & Stout. & Medium. & Thin. & Excel. & Good. & Medium. & Dull. \\
\hline $32 \cdot 7$ & $\mathbf{I}$ & $47 \cdot 7$ & $5^{2} \cdot 9$ & & 80 . & 20. & 6.6 & 26.6 & 26.6 & $?$ \\
\hline $21 \cdot 3$ & 2 & $49 \cdot 3$ & 56.6 & $4 \cdot 9$ & $77 \cdot 2$ & 14.9 & I6.6 & $45 \cdot 4$ & $3 I \cdot 2$ & 6.6 \\
\hline $13 \cdot 7$ & 3 & 50.8 & 59.6 & 10.5 & $74 \cdot 5$ & I 4.9 & $17 \cdot 5$ & $49 . I$ & 28 . & 5.2 \\
\hline
\end{tabular}

1 (Scot.) A supplementary dish or food used as a relish with other food, as with bread, porridge or potatoes. 
a suggestion in these figures that the inspection of school children may be applied to a furtherance of our industrial and hygienic as well as our educational interests."

The suggestions which emerged from a consideration of these facts were thus formulated:

"I. That in all communities a section of the population fails to participate in the hygienic advance of recent years, and that associated therewith there is much impaired health and defective physique, which means industrial inefficiency.

"2. That the limited measurements of school children, presently available, appear to indicate:

"(a) That their physical development is related to an economic standard of the family life, which may readily be expressed.

"(b) That their nutrition is similarly graded, and

"(c) That their mental inefficiency, as estimated by the masters, falls into line with both.

"3. That this lowering of the mental and physical condition of childhood tends to the production in inefficiency in the adult, from which again the vicious cycle is begun.

"4. That much educational energy is meanwhile misspent in endeavoring to educate children who are physically unfit, as evidenced by the small proportion of underfed children who reach a reasonable standard of proficiency, according to the masters' estimate.

"5. That in order to assist in preventing the production of industrial inefficients, food, and by implication the organized feeding of school children in certain districts is essential.

"6. That the most reliable way of ascertaining the distribution of underfed children is by a systematic medical inspection of them at schools."

\section{Housing.}

The literature of modern sanitation is replete with works on this subject, but three additions have recently been made to it, which are excellent for several reasons. They present the problem as existing in three important industrial municipalities-Birmingham, Manchester and Glasgow; and bring to the knowledge of the general reader much that has hitherto been known only to the sanitary officer and social worker. In this they cannot fail to have a direct educational value, and their excellence is enhanced by the 
uniform recognition that behind the structural decrepitude of the uninhabitable house and the adverse economic condition of its tenant (with both of which we have for so long been almost hopelessly familiar), there lies the element of the human soul which needs awakening. It is the recognition of this fact in these reports that makes them hopeful reading. For when the public conscience realizes that the slum-landlord and slum-tenant is there only because we have tolerated him, we shall have seen the beginning of the end of both. It is true that the reports supply no specific remedy for the conditions which they describe, and this, from the nature of the case, must be so. But in recognizing that for every separate aspect of the problem a different remedy is required, they have done much to guard future workers against repeating the errors of the past. The position has seldom been better put than in the following words from the Manchester and Salford report, which was prepared for the Citizens' Association for the Improvement of the Unwholesome Dwellings and Surroundings of the People, by $\mathrm{Mr}$. Marr, Secretary of the Association.

"To sum up. We see in our towns to-day many evils. Poor physique, impaired health, and premature senility; drunkenness, sexual immorality and other vice; betting and thriftlessness; decay of family life and lack of civic spirit; these are all too common. We find, too, poverty, houses unwholesome from many causes, lack of provision of open spaces and other means for healthy recreation, narrow and gloomy streets, an excessive amount of coal smoke, and a superabundance of public-houses. Endless discussion takes place among those interested in social reform as to which group of evils is cause, which effect. The truth seems to be that we have a vicious circle and that they are all both cause and effect. It is therefore necessary that all who are engaged in social work, all who are members of religious organisations, should join forces and at any sacrifice promote all measures for the welfare of the community."

With regard to present action, the reports may be said to be almost unanimous. "It cannot be too loudly proclaimed," wrote Sir John Simon now many years ago, "that an efficient administration of the sanitary laws is among the best helps which can be given to the poorer classes of the population; and that authorities who negligently or corruptly fail of their duties in such administration, are among the worst oppressors of the poor," and the [282] 
present reports lend what emphasis they can to this elementary principle of administrative action. It is true that the Manchester report expresses some hesitation when contemplating the possible displacement of people for whom no housing accommodation might be assumed to exist, but the Spectator in reviewing the Report commented thereon in terms so apposite that they may be introduced:

"What is wanted," says this reviewer, "is a clear and unmistakable statement of what the municipal authorities can do as the law stands. It will then be possible to tax them with neglect of duty if they leave any abuses unremedied. We do not all say that they may not have good reasons to give for their inaction, but only that the public has a right to be informed what those reasons are. The one that is most often given is the possibility that a vigorous use of their powers would only make the situation worse. 'To make,' says the report, 'large clearances in some parts of the city is desirable, but until provision has been made elsewhere for those who will be dishoused the authorities dare not take action lest matters become worse in other districts.' But why should this happen? In these other districts the laws against overcrowding only need to be enforced to prevent the dishoused population from drifting into them. We doubt whether public attention will ever be properly directed to this great problem until the results of proper action in the way of clearing hopelessly insanitary areas are visibly set forth in the shape of a number of people, without a roof over their heads and no possibility of finding one, placed in tents by the local authorities until better provision can be made for them. Oh, but look, it will be said, at the individual suffering which proceedings of this kind would inflict. But this suffering would at most be no greater than the suffering caused by living in houses in which not a single requirement of health or decency is forthcoming, with the difference, too, that the latter suffering is permanent, while the former is only temporary. Perhaps what is needed to wake the public conscience, sluggish enough at present, is some spectacle that shall impress the public imagination."

\section{Municipal Building.}

On this much discussed and very unsettled question the Birmingham Report expresses very definite and adverse views, which are shown in the following paragraphs therefrom: 
"Having ascertained the causes of the present state of affairs your committee then considered the remedies that have been suggested, and in the first place examined the pros and cons of municipal house building. They are of opinion that municipal house building will hinder the solution of the housing problem, for the following reasons:

"I. It is thought that municipal house building will reduce rents, because a corporation can borrow money cheaper than a private individual. But, in spite of this advantage, experience shows that municipal house building is more expensive than any other.

"2. Municipal houses are often let at cheaper rents than the surrounding houses; but this is only done by making a loss on the transaction. If the governing body could raise sufficient money to house all its citizens, municipal house building would simply result in the population paying more in rates and less for other items that go to make up house rent; but as the city authorities can only house a very small proportion, municipal house building must always in the future, as it has done in the past, result in taxing the many for the benefit of the few.

"3. The evidence shows that rate-aided competition in house building and letting will drive everyone else out of the trade, with the result that we shall have fewer houses provided in proportion to the demand, thereby creating a house famine, which is just what everyone wishes to avoid.

"4. It is urged that the governing body ought to provide good cheap houses for those who really cannot afford to pay the ruling price for new houses. The difficulty is to find out the respectable poor. Everyone experienced in philanthropic work knows how strenuously these people maintain their independence. They would not go to the corporation, the corporation would have to try and find them, a most difficult thing to do. People who apply for corporation houses will not all be those who have the greatest need for assistance, and the enquiry necessary to get at the truth would be of such an inquisitorial nature that no governing body could undertake it. Experience has shown that municipal houses are filled up immediately by those for whom they were never intended. If, on the other hand, an inquiry were thoroughly carried out, and the limit of wages for municipal tenants fixed, then 
there would be a gross injustice done to those men just above the limit, and they would have every inducement to earn lower wages, which is exactly contrary to what all reformers are working for.

"5. In connection with the foregoing it may be remarked that municipal house building is a form of rate-aided charity to the poorest class of the town. This charity comes out of the rates, which are compulsorily collected from all classes of the Community, either directly or indirectly, in the form of rent. The increased rates necessitated by municipal house building will press most heavily on the large class just above 'the poverty line,' and with increases for other purposes force many below it. Thus the result will be to still further increase, instead of to diminish, the proportion of the population for whom it is suggested rate-aided houses should be built.

"6. Supposing that municipal house building did result in reducing rent all over the city, this would only have the effect of subsidizing employers of labor. It is a well-known fact that wages follow rent. If rents go down, wages will also go down; and only the employers of labor will benefit. The evidence shows that there are many people who will only do just enough work to keep body and soul together; lower house rents would only encourage those to work less, and earn less money. Another effect of reducing rents in the city would be to tempt unskilled labor into the town. This would seriously injure the workers now in the city by making competition for employment in the city keener than ever. If the physique of Englishmen is to be maintained and improved, everything possible must be done to get people back to the country."

The Glasgow Report, on the other hand, makes a guarded recommendation which is limited in scope but worthy of trial if only for the reason that it gives the whilom dissolute tenant an opportunity of qualifying himself for active reputable citizenship. After recommending the municipality to undertake as an experiment the establishing of one or two lodging-houses in different districts of the city to accommodate poor couples and their children, the report proceeds :

"The commission recognize that if the foregoing recommendations, dealing with uninhabitable and overcrowded houses are carried out, there is likely to be a considerable amount of hardship 
to the dispossessed. Several thousands of people, from no fault of their own, will be dishoused, and it does not seem probable that they will be able to find other houses in the same neighborhood at the same rents as they were paying. Among those there will certainly be a proportion of thriftless and dissolute persons earning good wages, and it does not seem unreasonable that such persons should be compelled, by scarcity, to occupy better houses and pay higher rents; but there will as certainly be a proportion of respectable poor whose present wages will not allow them to pay a higher rent without some sacrifice. To these must be added the large though uncertain number of persons now living in overcrowded houses, who will require to seek other accommodation. If no special provision is made, it is probable that a public measure, which will admittedly confer a great benefit on the city as a whole, will press heavily on the small class least able to bear the burden. From the evidence submitted it appears that the corporation, on ground not exceeding 155. a yard, can build and let one and tworoomed houses at rents as low as the average of the houses which it is proposed to close or demolish, while paying all economic charges, including upkeep of property, interest and sinking fund."

In the foregoing circumstances, and without expressing any opinion upon the general policy of municipal housing, there seems to be a strong case in favor of the corporation providing a sufficient number of houses to obviate the hardship.

The commission therefor recommend (I) the erection by the corporation, up to the extent of the powers possessed by them under "The Glasgow Corporation Act, 1897," and "The Glasgow Corporation (Water and General) Order Confirmation Act, I902," of tenements of one and two-apartment houses, to be reserved exclusively for respectable people of the "poorest class," as defined by the former act, preference being given to those dispossessed and to the most necessitous; such houses to be situated, if possible, near to the area of dispossession, and to be under carefully selected caretakers.

If the foregoing recommendation be carried out, there still remains a class who seem to have some claim on exceptional provision, viz., those low-paid wage-earners who are dispossessed, and who, by reason of dissolute, disorderly and destructive habits, will find no room in the new corporation dwellings. These per- 
sons may not have any claim on the community if they will not reform; the community, however, in its own interest, should give them an opportunity to do so.

The commission therefore recommend (2) that an experiment should be made by the corporation in the erection of a building or buildings on the lines laid down by the city engineer, to be reserved for those who, while unable to show any factor's line or other certificate, are willing to submit to necessary regulations as to cleanliness, respectable living, order, and punctual payment of rent, with the view of rehabilitating their characters, and in time qualifying for a better house. The houses should be of the plainest construction, with indestructible fittings, and should be capable of being quickly and efficiently cleansed.

The commission also recommend (3) that, with the view of cheapening the construction of both classes of houses, some relaxation of the Building Regulations Act should be made.

Quite recently (November, 1904) the Edinburgh Social Union has issued its twentieth annual report, and we cannot help thinking that in it the true note of social reform has been struck. Again and always it must be that all social schemes will fail unless they reach the individual and create in hearts where hope is dead the aspirations which stimulate social activity and the ideals at which it aims.

The Union express their opinions in the following manner:

"When the Edinburgh Town Council began operations in I895 under the Housing of the Working Classes Act, we welcomed their schemes as a solution of the housing difficulty, and gladly accepted the offer of the management of the new houses which they built. But as the result of nine years' experience, during which more than five hundred families have been under our care in municipal houses, we have come to the conclusion that the work is not such as we wish to undertake.

"We feel convinced that the action of the municipality in providing houses for certain arbitrarily selected families, is discouraging the further supply of houses by private enterprise. Private builders and private companies are finding it exceedingly difficult to compete with large corporations (municipal undertakings), and this in itself is in our view a serious objection to the municipal system. Buildings with large courts and expensive fittings in each 
house cannot be provided at rents which the laboring class is able to pay, and can only be let to that class of tenants by providing a subsidy from the rates, or by an arrangement whereby a considerable proportion of the cost is written off for the public health account, as a public improvement. We do not believe that to maintain houses artificially at a cheap rent, is to help permanently to solve the housing question, and it is a serious tax upon the poorer rate payers, while if houses can be built to pay, there will immediately be plenty of people ready and anxious to build them.

"We are also of opinion that there is at present a sufficient sphere for municipal energy in the work of supervising the operations of private bodies and carrying out the by-laws regulating these in conformity with the demands of public morality and health. We acknowledge gratefully all that has been done by the sanitary department during recent years, but if the excellent by-laws of the town for landlord and tenant were universally enforced, a large part of the work which we at present undertake would no longer be necessary. In this direction we are only trying in certain selected districts to carry into effect the laws which the town has power to enforce in all.

"Our experience, lasting now over a period of eighteen years, reduces this housing problem entirely to a question of management. We have come to think that a badly-constructed house, well and efficiently managed, can be much less of a slum than one where there is no control, be it ever so well equipped. The problem, as we now see it, lies in the people and not in the houses. That the houses of our laboring classes should come to mean homes-that they should be clean and fresh and full of light and sweetness-we should all desire, but experience has taught us that in order to bring this to pass the people must desire it also. It is not even enough, nor is it possible to remove them to modern well-built houses, with all the most modern sanitary conveniences. The change is too sudden. The modern improvements they do not appreciate, and do not know how to employ. It is necessary to go to them where they are and as they are, and there teach them order and cleanliness, and the love of fresh air, and a knowledge of the uses and preparation of food. ...

"To attack the problem in the mass is, we think, a mistake. Each family must be treated by itself, and its members must learn [288] 
for themselves that while we as landlords have awakened to a new sense of our duties and responsibilities towards them, they on their side as citizens as well as tenants have very distinct and very definite duties and responsibilities which they must also realize and perform." 